\title{
Comparative Study of PID and FOPID Controller Response for Automatic Voltage Regulation
}

\author{
${ }^{1}$ Tushar Verma, ${ }^{2}$ Akhilesh Kumar Mishra \\ ${ }^{I}$ M.Tech. Scholar, Department of Electrical Engineering, United College of Engineering and Research, \\ Allahabad, Uttar Pradesh, INDIA. \\ ${ }^{2}$ Assistant Professor, Electrical Department, United College of Engineering and Research, Allahabad, Uttar \\ Pradesh, INDIA.
}

\begin{abstract}
The aim of this work is to design an automatic voltage regulation system by selection of FOPID parameters. In this work the advantage of FOPID controller over Conventional PID controller is discussed using MATLAB/Simulink. PID (proportional-integral-derivative) control is one of the earlier control strategies. Its early implementation was in pneumatic devices, followed by vacuum and solid state analog electronics, before arriving at today's digital implementation of microprocessors. But in the last decade, fractional-order dynamic systems and controllers has been studying widely in many areas of engineering and science. The concept of the fractional-order PID controllers was proposed by Podlubny in 1997[1]. He also demonstrated the better response of this type of controllers, in comparison with the classical PID controllers, when used for the control of fractional-order systems. A method is presented based on idea of the Ziegler-Nichols and Cohen Coon for the tuning of PID controller. Motivated from the fact that the optimization techniques depend on initial estimates, Valerio and Costa have introduced some Ziegler-Nichols-type tuning rules for FOPIDs.
\end{abstract}

Keywords: FOPID controller, PID Controller, Ziegler Nichols and Cohen-Coon tuning.

\section{INTRODUCTION}

The Automatic Voltage Regulator (AVR) is widely used in industrial application to obtain the stability and good regulation of different electrical apparatus. A voltage regulator is an electrical regulator designed to automatically maintain a constant voltage level. It may use an electromechanical mechanism, or passive or active electronic components. Depending on the design, it may be used to regulate one or more AC or DC voltages.

If the output voltage is too low, the regulation element is commanded up to a point to produce a higher output voltage by dropping less of the input voltage; if the output voltage is too high, the regulation element will normally be commanded to produce a lower voltage [2].

Proportional-Integral-Derivative controllers are widely being used in industries for process control applications. The merit of using PID controllers lie in its simplicity of design and good performance including low percentage overshoot and small settling time for slow industrial processes. The performance of PID controllers can be further improved by appropriate settings of fractional-I and fractional-D actions.

This paper attempts to study the behaviour of fractional PID controllers over integer order PID controllers. In a fractional PID controller, the I- and D-actions being fractional have wider scope of design. Naturally, besides setting the proportional, derivative and integral constants Kp, Td and Ti respectively, we have two more parameters: the power of ' $s$ ' in integral and derivative actions- $\lambda$ and $\mu$ respectively. Finding $[\mathrm{Kp}, \mathrm{Td}$, $\mathrm{Ti}, \lambda, \mu]$ as an optimal solution to a given process thus calls for optimization on the five-dimensional space.

The performance of the optimal fractional PID controller is better than its integer counterpart. Thus the proposed design will find extensive applications in real industrial processes.

This paper shows the comparative study of PID and FOPID controller response for automatic voltage regulation (AVR) system. The best parameters of for the response of Fractional-Order PID controller consist of proportional gain $\mathrm{Kp}$, integral gain $\mathrm{Ki}$, fractional-order of integrator $\lambda$, derivative gain $\mathrm{kd}$ and fractional-order of differentiator $\mu$ can be determinate for AVR system so that the controlled AVR system has a better control performance than other methods.

\section{LINEARIZED MODEL OF AN AVR SYSTEM}

The role of an AVR is to hold the terminal voltage magnitude of a synchronous generator at a specified level. A simple AVR system comprises four main components, namely amplifier, exciter, generator, and sensor [3]. 


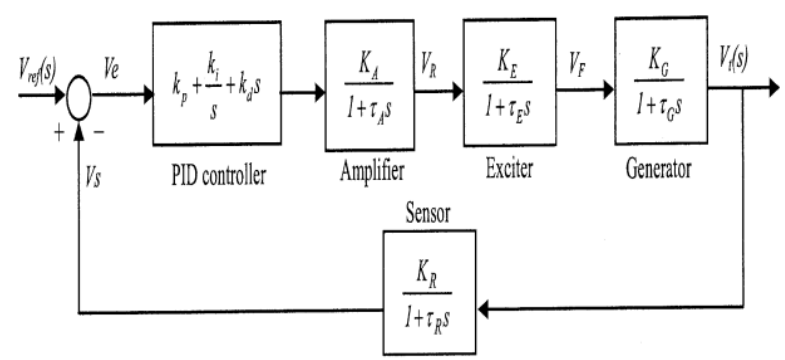

Fig.1 Linearized model of an AVR system

\begin{tabular}{|l|l|l|}
\hline Component & \multicolumn{1}{|c|}{$\begin{array}{c}\text { Transfer } \\
\text { Function }\end{array}$} & \multicolumn{1}{|c|}{ Parameter Range } \\
\hline Amplifier & $\mathrm{Ka} /\left(1+\mathrm{Ta}_{\mathrm{a}} \mathrm{s}\right)$ & $10<\mathrm{K}_{\mathrm{a}}<400,0.02<\mathrm{T}_{\mathrm{a}}<0.1 \mathrm{~s}$ \\
\hline Exciter & $\mathrm{K}_{\mathrm{e}} /\left(1+\mathrm{T}_{\mathrm{e}} \mathrm{s}\right)$ & $1<\mathrm{K}_{\mathrm{e}}<400,0.4<\mathrm{T}_{\mathrm{e}}<1 \mathrm{~s}$ \\
\hline Generator & $\mathrm{K}_{\mathrm{g}} /\left(1+\mathrm{T}_{\mathrm{g}} \mathrm{s}\right)$ & $\begin{array}{l}0.7<\mathrm{K}_{\mathrm{g}}<1,1<\mathrm{T}_{\mathrm{g}}<2 \mathrm{~s} \\
\text { from full load to no load }\end{array}$ \\
\hline Sensor & $\mathrm{K}_{\mathrm{s}} /\left(1+\mathrm{T}_{\mathrm{s}} \mathrm{s}\right)$ & $0.001<\mathrm{T}_{\mathrm{s}}<0.06 \mathrm{~s}$ \\
\hline
\end{tabular}

Table.1 Parameters value for AVR

(a) Amplifier Model:

The transfer function of amplifier model is

where $K \mathrm{~A}$ is a gain and TA is a time constant.

$$
\frac{V_{R}(s)}{V_{e}(s)}=\frac{K_{A}}{1+\tau_{A} s}
$$

\section{(b) Exciter Model:}

The transfer function of exciter model is

where $K \mathrm{E}$ is a gain and $\mathrm{TE}$ is a time constant.

$$
\frac{V_{F}(s)}{V_{R}(s)}=\frac{K_{E}}{1+\tau_{E} s}
$$

(c) Generator Model:

The transfer function of generator model is

where $K \mathrm{G}$ is a gain and $\mathrm{TG}$ is a time constant.

$$
\frac{V_{t}(s)}{V_{F}(s)}=\frac{K_{G}}{1+\tau_{G} s}
$$

\section{(d) Sensor Model:}

The transfer function of sensor model is

where $K \mathrm{R}$ is a gain and TR is a time constant.

$$
\frac{V_{S}(s)}{V_{t}(s)}=\frac{K_{R}}{1+\tau_{R} s}
$$

\section{THE INTEGER AND FRACTIONAL ORDER PID CONTROLLERS}

The PID controller is the most common general purpose controller in the today's industries. It can be used as a single unit or it can be a part of a distributed computer control system.

After implementing the PID controller, now we have to tune the controller; and there are different approaches to tune the PID parameters like P, I and D. The Proportional (P) part is responsible for following the desired setpoint while the Integral (I) and Derivative (D) part account for the accumulation of past errors and the rate of change of error in the process or plant, respectively.

PID controller consists of three types of control i.e. Proportional, Integral and Derivative control 


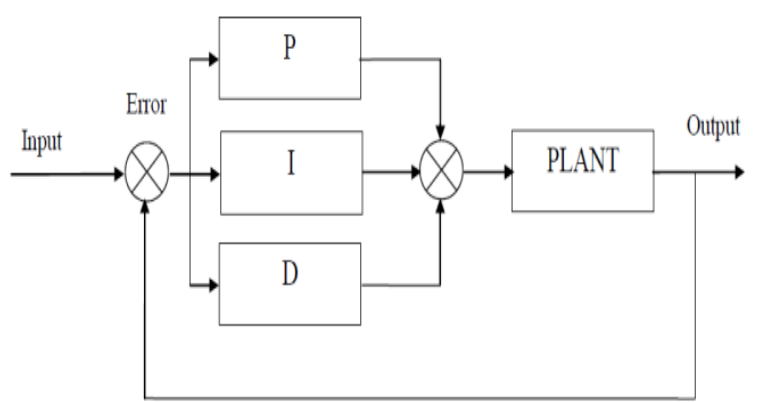

Fig.2 Schematic of PID controller

The system transfer function in continuous s-domain are given as

For $\mathrm{P}=\mathrm{K}_{\mathrm{P}, \mathrm{I}}=\mathrm{K}_{\mathrm{I}} / \mathrm{s}$ and $\mathrm{D}=\mathrm{K}_{\mathrm{d}} \mathrm{S}$

$G_{c}(s)=P+I+D=K_{p}+K_{i} / s+K_{d} s$

$G_{c}(s)=K_{p}\left\{1+1 / T_{i} s+T_{d} s\right\}$

Where $K_{p}$ is the proportional gain, $\mathrm{K}_{\mathrm{i}}$ is the integration coefficient and $\mathrm{K}_{\mathrm{d}}$ is the derivative coefficient.

$T_{i}$ is known as the integral action time or reset time and $T_{d}$ is the derivative action time or rate time.

In the last decade, fractional-order dynamic systems and controllers has been studying widely in many areas of engineering and science [4-8]. The concept of the fractional-order PID controllers was proposed by Podlubny in 1997. He also demonstrated the better response of this type of controllers, in comparison with the classical PID controllers, when used for the control of fractional order systems.

Fractional order control systems are described by fractional order differential equations. The FOPID controller is the expansion of the conventional PID controller based on fractional calculus.

A fractional PID controller therefore has the transfer function:

$G c(s)=K p+T i s^{-\lambda}+T d s^{\delta}$

The orders of integration and differentiation are respectively $\lambda$ and $\delta$ (both positive real numbers, not necessarily integers). Taking $\lambda=1$ and $\delta=1$, we will have an integer order PID controller. So we see that the integer order PID controller has three parameters, while the fractional order PID controller has five.

\section{CLASSICAL TUNING METHODS FOR CONTROLLER}

There are various tuning strategies based on an open-loop step response. While they all follow the same basic idea, they differ in slightly in how they extract the model parameters from the recorded response, and also differ slightly as to relate appropriate tuning constants to the model parameters. Naturally if the response is not sigmoidal or ' $\mathrm{S}$ ' shaped and exhibits overshoot, or an integrator, then this tuning method is not applicable.

\section{(a) PID TUNING}

\section{Ziegler-Nichols Tuning Method}

The PID tuning parameters as a function of the open loop model parameters $\mathrm{K}, \mathrm{T}$ and $\theta$ from the Process reaction curve derived by Ziegler-Nichols [9].

They often form the basis for tuning procedures used by controller manufacturers and process industry. The methods are based on determination of some features of process dynamics. The controller parameters are then expressed in terms of the features by simple formulas. The method presented by Ziegler and Nichols is based on a registration of the open-loop step response of the system, which is characterized by two parameters. First determined, and the tangent at this point is drawn. The intersections between the tangent and the coordinate axes give the parameters $\mathrm{T}$ and $\theta$. A model of the process to be controlled was derived from these parameters. This corresponds to modeling a process by an integrator and a time delay. Ziegler and Nichols have given PID parameters directly as functions of $\mathrm{T}$ and $\theta$. The behavior of the controller is as can be expected. The decay ratio for the step response is close to one quarter. It is smaller for the load disturbance. The overshoot in the set point response is too large. 


\begin{tabular}{|c|c|c|c|c|}
\hline \multicolumn{2}{|c|}{ Controller } & $\mathbf{K}_{\mathrm{p}}$ & $\mathbf{T}_{\mathbf{i}}$ & $\mathbf{T}_{\mathrm{d}}$ \\
\hline Ziegler- & $\mathbf{P}$ & $\mathrm{T} / \mathrm{K} \theta$ & - & - \\
\hline Nichols & PI & $0.9 \mathrm{~T} / \mathrm{K} \theta$ & $\theta / 0.3$ & - \\
\hline $\begin{array}{c}\text { Method } \\
\text { (Open } \\
\text { Loop) }\end{array}$ & PID & $1.2 \mathrm{~T} / \mathrm{K} \theta$ & $2 \theta$ & $0.5 \theta$ \\
\hline
\end{tabular}

Table.2 Ziegler Nichols open loop method

\section{Cohen-Coon Tuning Method}

Cohen and Coon based the controller settings on the three parameters $\theta$, $\mathrm{T}$ and $\mathrm{K}$ of the open loop step response. The main design criterion is rejection of load disturbances. The method attempts to position closed loop poles such that a quarter decay ration is achieved.

\begin{tabular}{|c|c|c|c|c|}
\hline \multicolumn{2}{|c|}{ Controller } & $\mathbf{K}_{\mathbf{p}}$ & $\mathbf{T}_{\mathbf{i}}$ & $\mathbf{T}_{\mathrm{d}}$ \\
\hline \multirow{3}{*}{$\begin{array}{l}\text { Cohen- } \\
\text { Coon } \\
\text { Method } \\
\text { (Open } \\
\text { Loop) }\end{array}$} & $\mathbf{P}$ & $\begin{array}{l}\text { T/KӨ.(1 } \\
+\Theta / 3 \mathrm{~T})\end{array}$ & & \\
\hline & PI & $\begin{array}{c}\mathrm{T} / \mathrm{K} \Theta .(0.9 \\
+\Theta / 12 \mathrm{~T})\end{array}$ & $\Theta .\{(30+3 \Theta / T) /(9+20 \Theta / T)\}$ & \\
\hline & PID & $\begin{array}{c}\mathrm{T} / \mathrm{K} \Theta .(4 / 3 \\
+\Theta / 4 \mathrm{~T})\end{array}$ & $\Theta .\{(32+6 \Theta / T) /(13+8 \Theta / T)\}$ & $\Theta .\{4 /(11+2 \Theta / T)\}$ \\
\hline
\end{tabular}

Table.3 Cohen Coon open loop method

\section{(b) FOPID TUNING}

Fractional-order calculus is an area of mathematics that deals with derivatives and integrals from noninteger orders. In other words, it is a generalization of the traditional calculus that leads to similar concepts and tools, but with a much wider applicability.

The numerical simulation of a fractional differential equation is not simple as that of an ordinary differential equation. Since most of the fractional-order differential equations do not have exact analytic solutions, so approximation and numerical techniques must be used.

\section{Ziegler-Nichols type tuning rules}

In practice, most solutions found with this optimization method are good enough, but they strongly depend on initial estimates of the parameters provided. Some may be discarded, because they are unfeasible or lead to unstable loops, but in many cases it is possible to find more than one acceptable FOPID [10].

In others, only well-chosen initial estimates of the parameters allow finding a solution. Valerio and Costa have introduced some Ziegler-Nichols-type tuning rules for FOPIDs. These tuning rules are applicable only for systems that have S-shaped step response.

\section{(a) First Set of Tuning Rules}

A first set of rules is given in Tables 4 and 5 . These are to be read as $P=-0.0048+0.2664 L+0.4982 T+0.0232 L 2-0.0720 T 2-0.0348 T L$ and so on. They may be used if $0.1<\mathrm{T}<50, \mathrm{~L}<2$

\begin{tabular}{|c|c|c|c|c|c|}
\hline & $\mathbf{K}_{\mathbf{p}}$ & $\mathbf{K}_{\mathbf{i}}$ & $\boldsymbol{\lambda}$ & $\mathbf{K}_{\mathbf{d}}$ & $\boldsymbol{\mu}$ \\
\hline $\mathbf{1}$ & -0.0048 & 0.3254 & 1.5766 & 0.0662 & 0.8736 \\
\hline $\mathbf{L}$ & 0.2664 & 0.2478 & -0.2098 & -0.2528 & 0.2746 \\
\hline $\mathbf{T}$ & 0.4982 & 0.1429 & -0.1313 & 0.1081 & 0.1489 \\
\hline $\mathbf{L}^{2}$ & 0.0232 & -0.133 & 0.0713 & 0.0702 & -.1557 \\
\hline $\mathbf{T}^{2}$ & -0.072 & 0.0258 & 0.0016 & 0.0328 & -0.025 \\
\hline $\mathbf{L T}$ & -0.0348 & -0.0171 & 0.0114 & 0.2202 & -.0323 \\
\hline
\end{tabular}

Table.4 Parameters for the first set of tuning rules when $0.1<\mathrm{T}<5$ 


\begin{tabular}{|c|c|c|c|c|c|}
\hline & $\mathbf{K}_{\mathbf{p}}$ & $\mathbf{K}_{\mathbf{i}}$ & $\boldsymbol{\lambda}$ & $\mathbf{K}_{\mathbf{d}}$ & $\boldsymbol{\mu}$ \\
\hline $\mathbf{1}$ & 2.1187 & -0.5201 & 1.0645 & 1.1421 & 1.2902 \\
\hline $\mathbf{L}$ & -3.5207 & 2.6643 & -0.3268 & -1.3707 & -.5371 \\
\hline $\mathbf{T}$ & -0.1563 & 0.3453 & -0.0229 & 0.0357 & -.0381 \\
\hline $\mathbf{L}^{\mathbf{2}}$ & 1.5827 & -1.0944 & 0.2018 & 0.5552 & 0.2208 \\
\hline $\mathbf{T}^{\mathbf{2}}$ & 0.0025 & 0.0002 & 0.0003 & -0.0002 & 0.0007 \\
\hline $\mathbf{L T}$ & 0.1824 & -0.1054 & 0.0028 & 0.263 & -.0014 \\
\hline
\end{tabular}

Table. 5 Parameters for the first set of tuning rules when $5<\mathrm{T}<50$

(b) Second set of tuning rules

A second set of rules is given in Table 6. These may be applied for $0.1<T<50$ and $\mathrm{L}<0.5$.

\begin{tabular}{|c|c|c|c|c|c|}
\hline & $\mathbf{K}_{\mathbf{p}}$ & $\mathbf{K}_{\mathbf{i}}$ & $\boldsymbol{\lambda}$ & $\mathbf{K}_{\mathbf{d}}$ & $\boldsymbol{\mu}$ \\
\hline $\mathbf{1}$ & -1.0574 & 0.6014 & 1.1851 & 0.8793 & 0.2778 \\
\hline $\mathbf{L}$ & 24.542 & 0.4025 & -0.3464 & -15.084 & -2.1522 \\
\hline $\mathbf{T}$ & 0.3544 & 0.7921 & -0.0492 & -0.0771 & 0.0675 \\
\hline $\mathbf{L}^{\mathbf{2}}$ & -46.732 & -0.4508 & 1.7317 & 28.0388 & 2.4387 \\
\hline $\mathbf{T}^{\mathbf{2}}$ & -0.0021 & 0.0018 & 0.0006 & 0 & -0.0013 \\
\hline $\mathbf{L T}$ & -0.3106 & -1.205 & 0.038 & 1.6711 & 0.0021 \\
\hline
\end{tabular}

Table. 6 Parameter for the second set of tuning rules for $0.1<T<50$ and $\mathrm{L}<0.5$

\section{SIMULINK MODEL OF AVR}

The Simulink model of AVR is shown in Fig 3. This model consist the mathematical function of amplifier, exciter and generator.

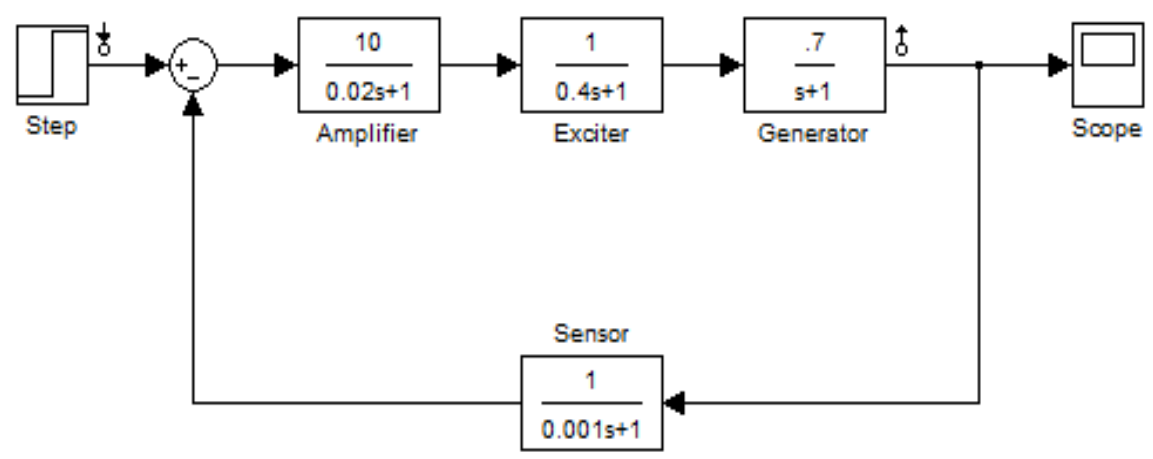

Fig.3 Simulink model of AVR

The Simulink model of various tuning method for AVR using PID tuned by Ziegler Nichols and Cohen Coon and FOPID controller tuned by Ziegler Nichols is shown in Fig 4. 


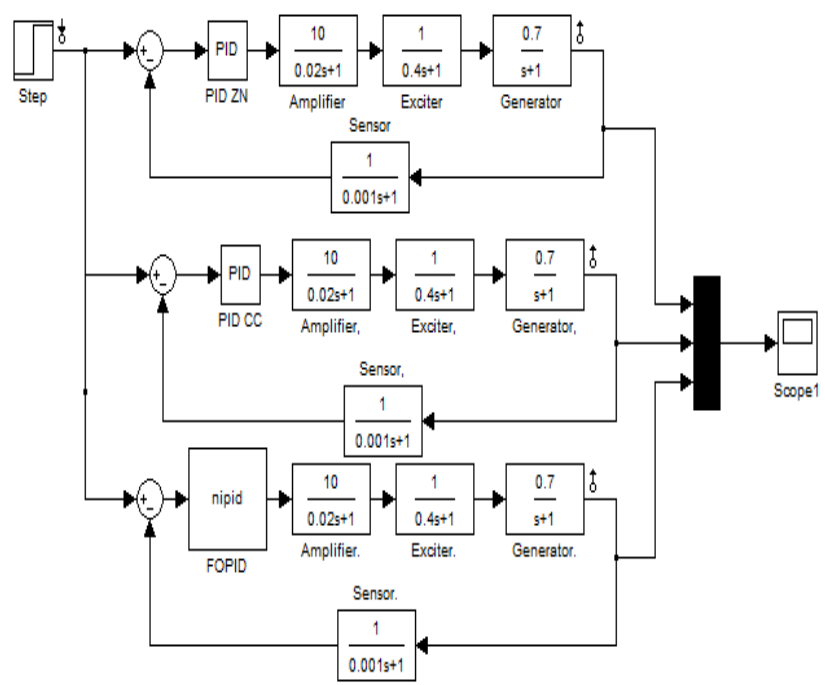

Fig.4 Simulink model of various tuning methods

\section{RESULT AND DISCUSSION}

The Simulink model in Fig. 3 \& 4 was simulated and the plots for various tuning method were observed. Fig 6 shows the Step response of AVR using PID tuned by Ziegler Nichols, Fig 7 shows the step response of AVR using PID tuned by Cohen Coon. and Fig 7 shows the Step response of AVR using FOPID controller.

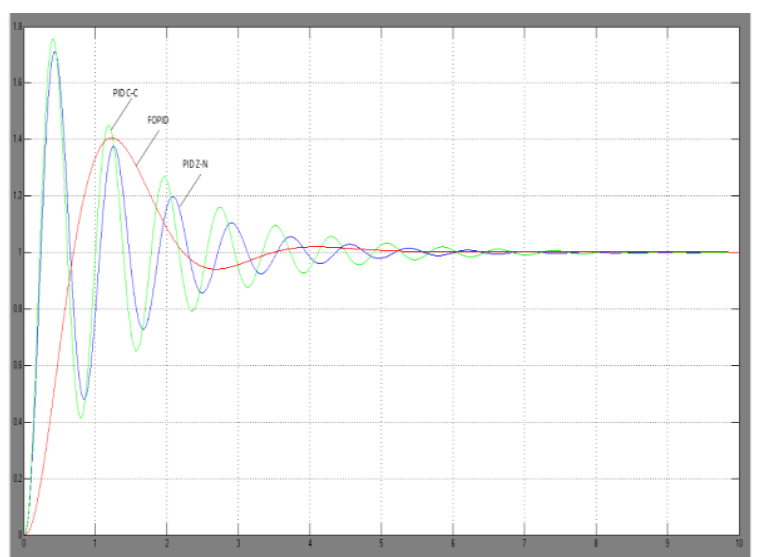

Fig.5 Response of PID tuned with Zeigler Nichols \& Cohen Coon and FOPID tuned with Zeigler Nichols for AVR

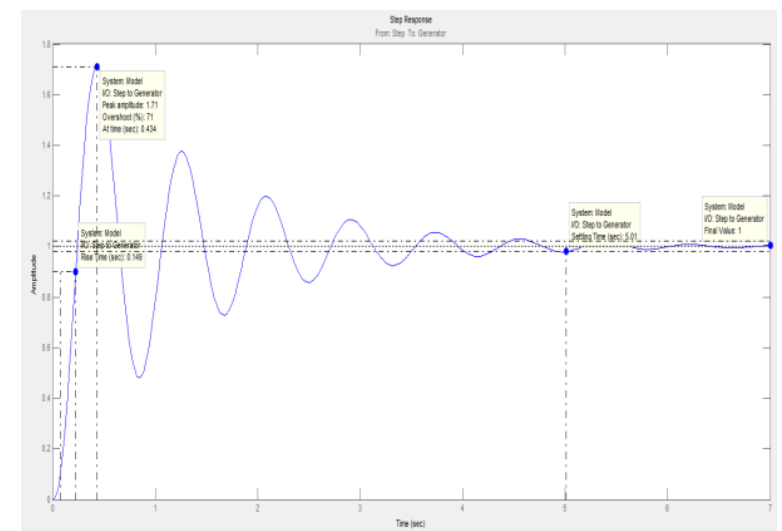

Fig.6 Step response of AVR using PID tuned by Ziegler Nichols 


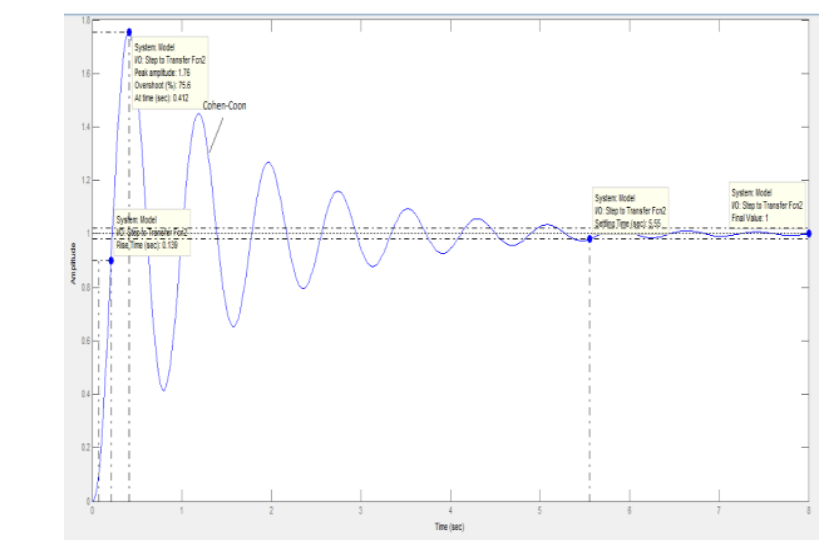

Fig.7 Step response of AVR using PID tuned by Cohen Coon

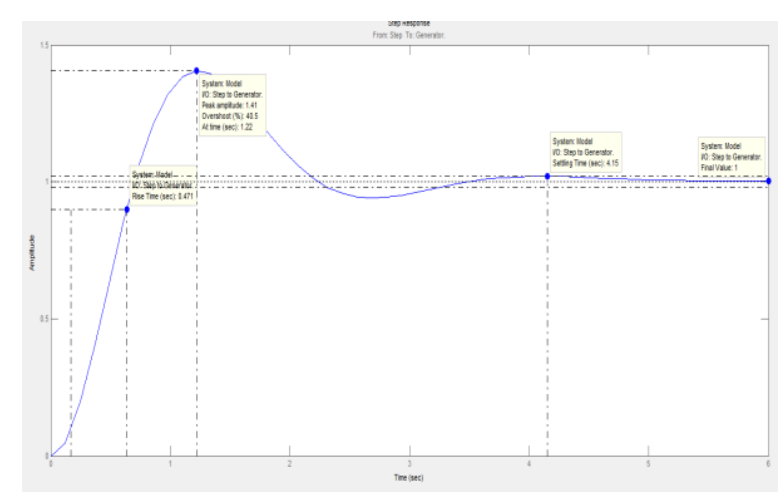

Fig.8 Step response of AVR using FOPID

It can be seen from the comparison table that while using the FOPID controller tuned by Ziegler Nichols the overshoots obtained is less as compared to the case when the PID Controller was tuned via conventional methods i.e. Ziegler Nichols and Cohen Coon method. The settling time is also lesser in case of the FOPID controller, also the rise time is reduced. The FOPID controller tuned by Z-N tuning rule tends to faster response of AVR. It can be observed from Fig 6 and 7 that the PID controller tuned by Ziegler Nichols and Cohen Coon have larger overshoot than FOPID controller attain a steady state with larger settling time.

\begin{tabular}{|c|c|c|c|}
\hline & \multicolumn{2}{|c|}{ PID } & FOPID \\
\hline \multirow{2}{*}{ Parameters } & $\begin{array}{c}\text { Ziegler } \\
\text { Nichols }\end{array}$ & $\begin{array}{c}\text { Cohen } \\
\text { Coon }\end{array}$ & $\begin{array}{c}\text { Ziegler } \\
\text { Nichols }\end{array}$ \\
\hline $\mathbf{K}_{\mathbf{p}}$ & 2.7719 & 3.3221 & 0.5543 \\
\hline $\mathbf{K}_{\mathbf{i}}$ & 3.009 & 3.4323 & 0.5841 \\
\hline $\mathbf{K}_{\mathbf{d}}$ & 0.6384 & 0.5159 & 0.2247 \\
\hline $\boldsymbol{\lambda}$ & - & - & -1.0814 \\
\hline $\boldsymbol{\mu}$ & - & - & 1.3628 \\
\hline $\mathbf{T}_{\mathbf{r}}(\mathbf{s e c})$ & 0.149 & 0.139 & 0.471 \\
\hline $\mathbf{T}_{\mathbf{s}}(\mathbf{s e c})$ & 5.01 & 5.55 & 4.15 \\
\hline $\mathbf{M}_{\mathbf{p}}(\mathbf{\%})$ & 71 & 75.6 & 40.5 \\
\hline
\end{tabular}

Table.7 Comparative values of different parameters obtained by PID and FOPID controllers

\section{CONCLUSION}

Performance comparisons of FOPID and PID controllers have been reviewed and it is found that response of FOPID controller is better than PID controller. The settling time and rise time of the response acquired by FOPID controller is found to be less as comparison to response acquired by PID controller. 


\section{ACKNOWLEDGMENT}

This work was supported by Mr. Akhilesh Kumar Mishra. Special Thanks to all faculty members of Electrical Engineering Department of United College of Engineering \& Research, Allahabad India, Specially Head of Department Mr. Abdul Zeeshan for their co-operation.

\section{REFERENCES}

[1] Podlubny, I.: Fractional-order systems and PI_D_controllers, IEEE Trans. On Automatic Control, vol.44, no.1, pp. 208 213, 1999.

[2] M. Rabiul Alam, Rajib Baran Roy, S.M. Jahangir Alam, Dewan Juel Rahman International Journal of Electrical \& Computer Sciences IJECS-IJENS Vol: 11 No: 05

[3] H. Yoshida, K. Kawata, and Y. Fukuyama, "A particle swarm optimization for reactive power and voltage control considering voltage security assessment," IEEE Trans. Power Syst., vol. 15, pp. 12321239, Nov. 2000.

[4] K. B. Oldhamand and J. Spanier, "The Fractional Calculus", Academic Press, New York, (1974).

[5] C. H. Lubich, "Discretized fractional calculus", SIAM Journal on Mathematical Analysis, (1986), pp. 704-719.

[6] K. S. Miller and B. Ross, "An Introduction to the Fractional Calculus and Fractional Differential Equations", Wiley, New York, (1993).

[7] A. Oustaloup, "Fractional order sinusoidal oscillators: optimization and their use in highly linear FM modulators", IEEE Transactions on Circuits and Systems, (1981), pp.1007-1009.

[8] M. Chengbin and Y. Hori, "The application of fractional order PID controller for robust two-inertia speed control", Proceedings of the 4th International Power Electronics and Motion Control Conference, Xi'an, (2004) August.

[9] F. Merrikh-Bayat, M. Karimi-Ghartemani, "Method for designing FOPID stabilisers for minimum-phase fractional-order systems", IET Control Theory Appl., vol. 4, Issue 1, (2010), pp. 61-70.

[10] Padula, F., Visioli, A., (2010a). Tuning rules for optimal PID and fractional-order PID controllers, Journal of Process Control, doi:10.1016/j.jprocont.2010.10.006 